\title{
Stack-and-draw microstructured optical fiber with Ge28Sb12Se60 chalcogenide glass
}

Shengling, Wu; Fleming, Simon; Kuhlmey, Boris T.; Hayashi, Juliano G.; Ebendorff-Heidepriem, Heike; Stefani, Alessio

Published in:

Bragg Gratings, Photosensitivity and Poling in Glass Waveguides and Materials, BGPPM 2018

Link to article, DOI:

10.1364/BGPPM.2018.JTu5A.69

Publication date:

2018

Document Version

Peer reviewed version

Link back to DTU Orbit

Citation (APA):

Shengling, W., Fleming, S., Kuhlmey, B. T., Hayashi, J. G., Ebendorff-Heidepriem, H., \& Stefani, A. (2018).

Stack-and-draw microstructured optical fiber with Ge28Sb12Se60 chalcogenide glass. In Bragg Gratings,

Photosensitivity and Poling in Glass Waveguides and Materials, BGPPM 2018 [JTu5A.69] Optical Society of America (OSA). Optics InfoBase Conference Papers Vol. Part F98-BGPPM 2018

https://doi.org/10.1364/BGPPM.2018.JTu5A.69

\section{General rights}

Copyright and moral rights for the publications made accessible in the public portal are retained by the authors and/or other copyright owners and it is a condition of accessing publications that users recognise and abide by the legal requirements associated with these rights.

- Users may download and print one copy of any publication from the public portal for the purpose of private study or research.

- You may not further distribute the material or use it for any profit-making activity or commercial gain

- You may freely distribute the URL identifying the publication in the public portal 


\title{
Stack-and-draw microstructured optical fiber with $\mathrm{Ge}_{28} \mathrm{Sb}_{12} \mathrm{Se}_{60}$ chalcogenide glass
}

\author{
Wu Shengling, ${ }^{1}$ Simon Fleming, ${ }^{1}$ Boris T. Kuhlmey ${ }^{1,2}$ Juliano G. Hayashi, ${ }^{1}$ \\ Heike Ebendorff-Heidepriem ${ }^{3}$ and Alessio Stefani, ${ }^{1,4}$ \\ ${ }^{1}$ Institute of Photonics and Optical Science (IPOS), School of Physics, The University of Sydney, NSW 2006, Australia \\ ${ }^{2}$ Centre for Ultrahigh Bandwidth Devices for Optical Systems (CUDOS), School of Physics, The University of Sydney, NSW 2006, Australia \\ ${ }^{3}$ Institute for Photonics and Advanced Sensing (IPAS), University of Adelaide, SA 5005, Australia \\ ${ }^{4}$ DTU Fotonik, Department of Photonics Engineering, Technical University of Denmark, DK-2800 Kgs. Lyngby, Denmark \\ shengling.wu@sydney.edu.au
}

\begin{abstract}
A microstructured optical fiber based on nontoxic and commercially available $\mathrm{Ge}_{28} \mathrm{Sb}_{12} \mathrm{Se}_{60}$ chalcogenide glass was fabricated by the stack-and-draw method. This fiber has potential applications including supercontinuum generation and metamaterials in the midinfrared region.

OCIS codes: (060.4005) Microstructured fibers; (160.4330) Nonlinear optical materials; (060.2390) Fiber optics, infrared.
\end{abstract}

\section{Introduction}

Microstructured optical fibers (MOFs) have unique properties, including high birefringence, tunable dispersion, and ultrahigh nonlinearities [1]. Based on these properties, MOFs have been widely used in many applications such as high harmonic generation, atom and particle guidance, and supercontinuum generation $[1,2]$. However, the use of MOFs, which are mostly made of silica, is difficult to expand into the mid-infrared region $(3 \sim 15 \mu \mathrm{m})$ due to the high material absorption beyond $2 \mu \mathrm{m}$. Soft glasses, especially chalcogenide glasses, have been used to overcome this limitation, because of their high transparency and nonlinear material response in the mid-infrared region [3-5]. The widely used $\mathrm{As}_{2} \mathrm{~S}_{3}$ and $\mathrm{As}_{2} \mathrm{Se}_{3}$ chalcogenide glasses contain toxic arsenic and would therefore be desirable to avoid such glasses. There is no report to date, to our knowledge, using arsenic-free and commercially available chalcogenide glass to fabricate MOF by the stack-and-draw method.

Here, we use the arsenic free $\mathrm{Ge}_{28} \mathrm{Sb}_{12} \mathrm{Se}_{60}$ chalcogenide glass (IG5, IRradiance Glass Inc.), to fabricate MOF by the stack-and-draw method for the first time.

\section{Thermal stability of IG5 glass}

The thermal stability of a glass is dominant in determining whether a glass can be used for drawing optical fiber, and ideally the difference between glass transition temperature and crystallization temperature should be as large as possible. This can be studied by using differential scanning calorimetry (DSC). The results shown in Fig.1(a) reveal that the IG5 glass transition temperature $\left(\mathrm{T}_{\mathrm{g}}\right)$ is $279^{\circ} \mathrm{C}$, and there is no obvious crystallization point up to $420^{\circ} \mathrm{C}$, which indicates the IG5 glass as a very promising material for drawing optical fibers. Generally, drawing chalcogenide glass optical fiber happens with viscosity between the Littleton softening point $\left(10^{6.6} \mathrm{~Pa} . \mathrm{s}\right)$ and $10^{5} \mathrm{~Pa} . \mathrm{s}$ [6], so the drawing temperature for IG5 glass is calculated to be between $348^{\circ} \mathrm{C}$ to $370^{\circ} \mathrm{C}$ according to the two-parameter Arrhenius equation for IG5 glass [7]. Interestingly, we found IG5 glass can be drawn from furnace setting temperature of $325^{\circ} \mathrm{C}$ to $395^{\circ} \mathrm{C}$ without crystallization after performing several drawing experiments, and assessing the absence of crystallization with microscopy, while the other reported Ge-Sb-Se glass $\left(\mathrm{Ge}_{25} \mathrm{Sb}_{10} \mathrm{Se}_{65}\right)$ showed a 'skin-like' crystallization layer when it was drawn into fiber [8]. The IG5 glass stability at high temperature was tested by thermogravimetric analysis (TGA) in air. No weight loss up to $600^{\circ} \mathrm{C}$ was observed in the result (Fig. 1(b)), which indicates there is no out-gassing from the glass when drawing in atmospheric condition.
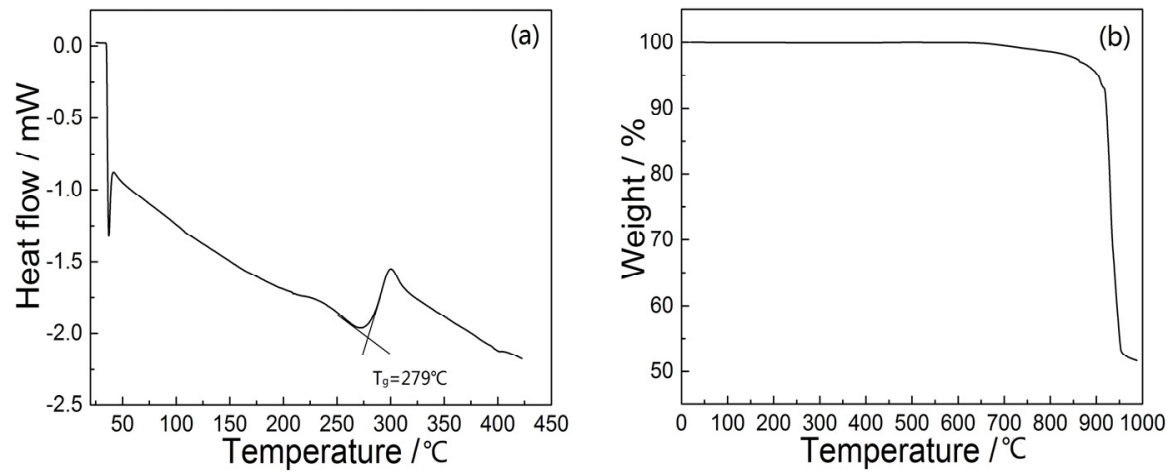

Figure.1 DSC (a) and TGA (b) tests of IG5 glass 


\section{Fabrication of IG5 glass MOF}

The fabrication of IG5 glass MOF begins from an IG5 chalcogenide glass billet (Fig. 2(a)), which is firstly extruded into a tube (Fig. 2(b)) using a specifically designed die. Capillaries are drawn from the extruded glass tube (Fig. 2(c)), then stacked into a hexagonal arrangement and inserted into a jacketing tube to realize the fiber preform (Fig. 2(d)). This assembly is then drawn into a microstructured cane under 0.8 Bar vacuum. A second jacket tube is used to sleeve the cane and suitable pressure should be applied in the microstructured cane to obtain a MOF with the desired suspended core structure. The amount of pressure required could be found empirically, however, the high cost and limited availability of the glass led us to investigate more deeply the dynamics of the viscous glass during the drawing process. We performed simulations on the evolution of inner and outer diameters of IG5 glass fiber with a fluid-mechanics model making use of asymptotic analysis [9] including dependence on the applied pressure, and confirmed the results with experiments on single capillaries and in a second stage on microstructures. For the preform shown in Fig. 2(d), 60 mbar of pressure was introduced, in agreement with the simulations, in the final drawing process and a $40 \mathrm{~cm}$ long IG5 MOF was successfully obtained (Fig. 2(e)). The cross-section of the final IG5 MOF is shown in Fig. 2(f). One hole collapsed due to one capillary breaking during the process. Nevertheless, the overall structure was preserved, and a structure with six holes and four suspended cores was obtained, with the smallest suspended core being about $7 \mu \mathrm{m}$, the outside fiber dimension around $400 \mu \mathrm{m}$, and the sizes of holes $27 \sim 53 \mu \mathrm{m}$.

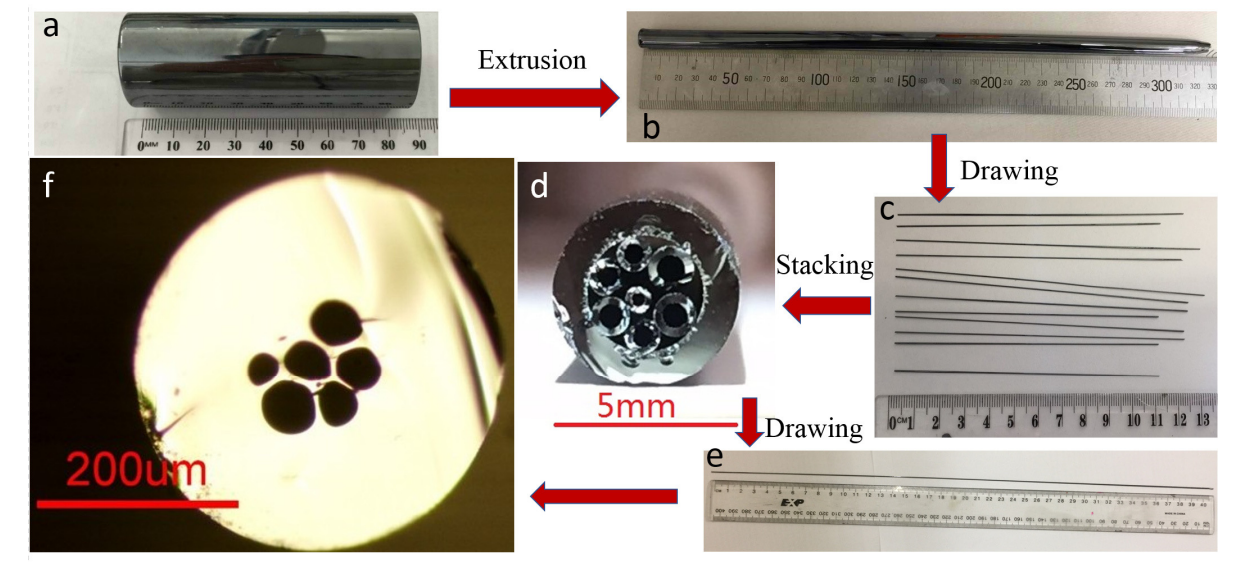

Figure.2 Process flow chart of fabrication IG5 MOF: (a) glass billet, (b) extruded tube, (c) glass capillaries, (d) preform, (e) IG5 MOF, (f) microscope image of IG5 MOF

\section{Conclusion}

We investigated a nontoxic and commercially available chalcogenide glass: $\mathrm{Ge}_{28} \mathrm{Sb}_{12} \mathrm{Se}_{60}$. The glass thermal properties and stability showed the glass to be suitable for fiber drawing. We also realized a MOF with four suspended cores obtained with the stack-and-draw method for the first time with this glass. Such structure already offers an opportunity for supercontinuum generation in the mid-infrared region. We also numerically investigated the fluid dynamics of the glass during the process and with this knowledge various structures can now be realized. Furthermore, this IG5 MOF lays the foundation of fabricating chalcogenide glass wire array metamaterials with potential applications including mid-infrared hyperlenses.

\section{References}

[1] P. Russell, "Photonic crystal fibers," Science, 2003.

[2] J. M. Dudley et al "Supercontinuum generation in photonic crystal fiber," Rev. Mod. Phys, 1135-1184, 2006.

[3] Q. Coulombier, et al, "Casting method for producing low-loss chalcogenide microstructured optical fibers," Opt. Express, 9107-9112, 2010.

[4] M. El-Amraoui et al, "Microstructured chalcogenide optical fibers from $\mathrm{As}_{2} \mathrm{~S}_{3}$ glass: towards new IR broadband sources," Opt. Express, 26655-26665, 2010.

[5] C. Yi et al, "Fabrication and characterization of $\mathrm{Ge}_{20} \mathrm{Sb}_{15} \mathrm{~S}_{65}$ chalcogenide glass for photonic crystal fibers," Appl. Phys. B, 653-658, 2014.

[6] J.-L. Adam et al, Chalcogenide glasses: preparation, properties and applications: Woodhead Publishing, 2014.

[7] H. Ebendorff-Heidepriem et al, "Analysis of glass flow during extrusion of optical fiber preforms," Opt. Mater. Express, 204-320, 2012.

[8] H. Parnell et al, "Ge-Sb-Se glass fiber-optics for in-vivo mid-infrared optical biopsy," in Optical Biopsy XIV: Toward Real-Time Spectroscopic Imaging and Diagnosis. 970309, 2016.

[9] G. Luzi et al, "Influence of surface tension and inner pressure on the process of fibre drawing," J. Lightwave Technol, 1882-1888, 2010. 